\title{
Basit dirsek çıkıkları
}

\section{Simple elbow dislocations}

\author{
Mehmet Oğuz Durakbaşa
}

Haydarpaşa Numune Eğitim ve Araştırma Hastanesi, Ortopedi ve Travmatoloji Kliniği, İstanbul

Basit dirsek çıkığı yalnız yumuşak doku yaralanması ya da eklem dışı kopma kırıklarıyla birlikte olan dirsek çıkıklarını içermektedir; çıkığın yönü ya da süresine göre sınıflandırılmaktadır. Etiyolojik olarak birinci sırada, eli açık yere düşme gelmektedir. Fizyopatolojisinde, ön kolun patolojik dış rotasyonunun dirsek çıkığına neden olduğu ileri sürülmektedir. Vücudun ağırlığıyla oluşan aksiyel yüklenmeyle birlikte dirseğe gelen valgus ya da varus yüklenmeleri, yaralanma şiddetini ve dokuların yaralanma sırasını belirlemektedir. Dokulardaki yaralanma seyrinin, posterolateral dirsek çıkıklarında valgus yüklenmesiyle mediyalden laterale doğru, posteromediyal dirsek çıkıklarında ise varus yüklenmesiyle lateralden mediyale doğru olduğu bildirilmektedir. Bu tip yaralanmalarda koronoid çıkıntıdaki kopma kırıkları instabilite ölçütü olarak kabul edilmektedir. Basit dirsek çıkığı tanısı klinik ve radyografik tetkik ile konur. Özellikle adolesan dönemde, mediyal ve lateral epikondil kopma kırıklarının teşhisi için sağlam tarafla karşılaştırmalı grafiler çekilmelidir. Kopma kırıkları ve eklem içi osteokondral kırık parçalarını araştırmaya yönelik olarak her hastaya bilgisayarlı tomografi (BT) ve üç boyutlu bilgisayarlı tomografi (3D-BT) yapılmalıdır. Stabil olmayan çıkıklarda ise yumuşak doku yaralanmasının boyutlarını görmek amacıyla manyetik rezonans (MR) görüntüleme tercih edilir. Basit dirsek çıkıklarının tedavisinde, kapalı redüksiyon sonrası stabil olanlarda 10 günü geçmeyen tespit ve hemen hareket, stabil olmayanlarda pronasyonda breys, pronasyonda ekstansiyon bloklu breys ya da cerrahi tedavi uygulanır. Dirsek çıkığı sonrası görülen komplikasyonlar; dirsek ekleminde kontraktür, heterotopik kemikleşme, nörovasküler yaralanma, Essex-Lopresti yaralanması ve rezidüel instabilitedir.

Anahtar sözcükler: basit dirsek çıkığı; patolojik ön kol eksternal rotasyonu; instabilite; komplikasyonlar
Simple elbow dislocation consists of the elbow dislocations with soft-tissue injuries only or with extra-articular avulsion fractures; it is classified according to the direction or the timing of the dislocation. Fall on an outstretched hand is the most common etiologic mechanism. It is postulated that pathologic external forearm rotation results in an elbow dislocation. Axial loading transmitted through the body to the elbow joint as well as valgus or varus loading determines the grade and the sequence of the soft tissue injury. It is reported that the sequence of injury is from medial to lateral in posterolateral dislocation and from lateral to medial in posteromedial dislocation as a consequence of valgus and varus loading respectively. Coronoid process avulsion fracture is accepted as an instability criterion for this kind of dislocations. Simple elbow dislocation is diagnosed by clinical and radiographic examination. Radiographs of the opposite side are very useful in detecting the medial and lateral epicondyle fractures especially in adolescents. Computerized tomography and three dimensional computerized tomography have to be taken for every patient in order to detect the avulsion fractures or intraarticular osteochondral fracture fragments. Magnetic resonance (MR) imaging is the preferred examination tool in unstable elbow dislocation for the assessment of the soft tissue injury. Stable simple elbow dislocations are treated by closed reduction, splinting not more than 10 days, and applying immediate range of motion exercises; for unstable ones, turnbuckle orthosis in pronation with and without an extension block or surgery are indicated. Contracture, heterotopic ossification, neurovascular injury, Essex-Lopresti injury and residual instability are the complications encountered after simple elbow dislocations.

Key words: simple elbow dislocation; pathologic external forearm rotation; instability; complications
B asit dirsek çıkığı yalnız yumuşak doku yaralanması ya da eklem dışı kopma kırıklarıyla birlikte olan dirsek çıkığı olarak tanımlanır. Eklem dışı kopma kırıkları humerus mediyal ve lateral epikondil kırıklarıyla, eklem stabilitesini bozmayan koronoid çıkıntı kırıklarını içerir. ${ }^{[1]}$ Kompleks dirsek çıkığı ise dirseğin eklem içi kırıklarıyla birlikte olan çıkığı olarak tanımlanmaktadır. ${ }^{[2]}$ Dirsek çıkığı, üst ekstremite çıkıkları içerisinde sıklık bakımından erişkinde omuz çıkığından sonra ikinci sırada, çocuklarda ise birinci sırada

- İletişim adresi: Uzm. Dr. Mehmet Oğuz Durakbaşa, SOYAK Gökyüzü Konutları, C Blok, D: 45; Barbaros Mah., Karayolları Site Sok., no: 5, Üsküdar, İstanbul Tel: 0532 - 7652442 e-posta: odurakbasa@yahoo.com

- Geliș tarihi: 10 Ocak $2014 \quad$ Kabul tarihi: 10 Ocak 2014 
yer almaktadır. ${ }^{[3]}$ Yıllık sıklığının 100.000 'de 6-8, en yüksek sıklığın 10-20 yaş aralığında olduğu bildirilmektedir. ${ }^{[4]}$

Bu derlemede dirsek eklemi stabilitesi, dirsek çıkığı etiyoloji ve fizyopatolojisi, sınıflandırma, klinik ve radyolojik değerlendirme, tedavi yöntemleri, tedavi sonrası takip ve rehabilitasyon programı, tedavi sonuçları ve komplikasyonlarla ilgili bilgi verilecektir.

\section{DIRSEK EKLEMI STABILITESI}

Eklemin kemik yapısı, mediyal kollateral bağ (MCL) kompleksi ve lateral kollateral bağ (LCL) kompleksi birincil statik stabiliteyi; radius başı, fleksör, pronator ve ekstansör kasların origoları ile eklem kapsülü ikincil statik stabiliteyi sağlayan yapılardır. Dinamik stabiliteyi sağlayan yapılar ise biseps, triseps, brakiyalis ve ankoneus kaslarıdır (Şekil 1)..[2] Ekstansiyonda valgus stresine karşı stabiliteyi \%30 MCL kopleksi, \%40 anterior eklem kapsülü, \%30 eklemin kemik yapısı sağlar; $90^{\circ}$ fleksiyonda ise bu oranlar sırasıly $\% 55, \% 10$ ve \%35 olarak değişir. Ekstansiyonda varus stresine karşı stabiliteyi \%15 LCL kompleksi, \%30 anterior eklem kapsülü, \%55 eklemin kemik yapısı sağlar; $90^{\circ}$ fleksiyonda ise bu oranlar sırasıyla $\% 10, \% 15$ ve $\% 75$ olarak değişir. ${ }^{[5]}$

\section{DIRSEK ÇIKIĞI ETIYOLOJi VE FIZYOPATOLOJISI}

O'Driscoll ve arkadaşlarının yaptığı deneysel çalışmada, eli açık yere düşen insanda posterior dirsek çıkığının, aksiyel yüklenme, gövdenin el üzerinde internal rotasyonu sonucu ön kolun supinasyonu ve dirseğin valgusu ile meydana geldiği bildirilmiştir. ${ }^{[6]}$ Dirsek posterior çıkığının klinik evreleri; lateral ulnar kollateral bağın yırtıldığı posterolateral rotatuvar instabilite (Evre 1), anterior ve posterior kapsülün yırtıldığı dirsek eklemi subluksasyonu ya da kilitlenmesi (Evre 2) ve MCL'nin yırtıldığı dirsek dislokasyonu (Evre 3) olarak tanımlanmıştır. Bu deneysel çalışmada, MCL'nin anterior bandının 13 kadavranın 12'sinde sağlam kaldığı tespit edilerek, posterior dirsek çıkığının çoğunda MCL'nin salim olacağı vurgulanmıştır. Posterior dirsek çıkığı oluşum mekanizmasında, O'Driscoll ve arkadaşlarının bildirdiği ön kol supinasyonu daha sonra patolojik ön kol eksternal rotasyonu (pathologic external forearm rotation, PEFR) adıyla literatüre geçmiş ve PEFR, ön kolun radius başını kapitellumdan dışarı atacak şekilde aşırı derecede eksternal rotasyona gelmesi olarak tanımlanmıştır. ${ }^{[7]} \mathrm{Bu}$ patolojik hareketi fizyolojik ön kol supinasyonundan ayıran, radius ve ulnanın humerusa göre birlikte eksternal rotasyona gelmesidir. Bu rotasyon sırasında koronoid çıkıntının

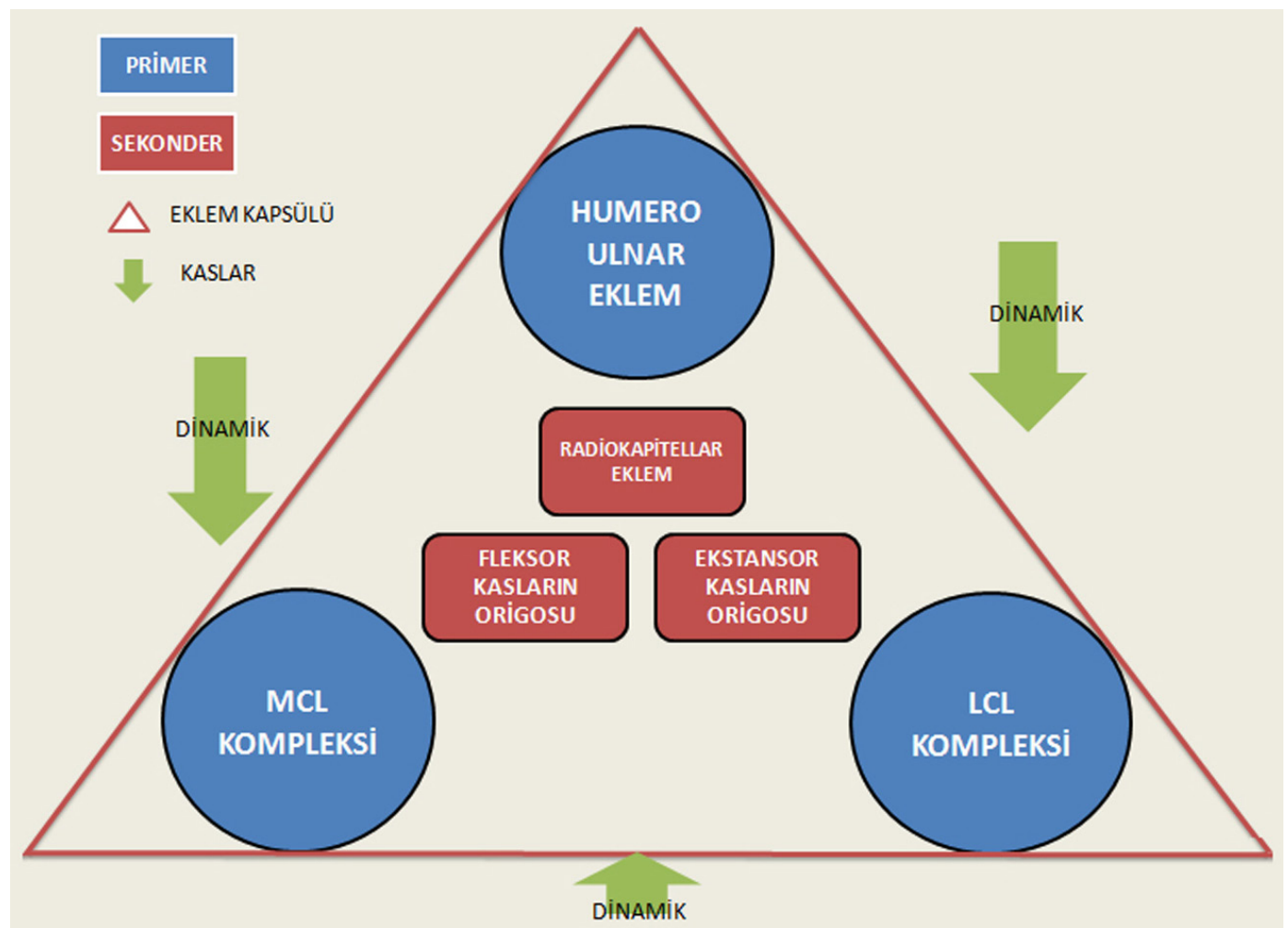

Şekil 1. Dirsek eklemi stabilitesi. 
yüksekliğinin ve troklea ile ilintili eklem stabilizasyonunu sağlayıcı etkisinin azaldığı, dirsek ekleminin kemiksel stabilitesini kaybederek, ön koldan kurvetli bir aksiyel yüklenme gelirse posteriora çıkacağı bildirilmiştir. Ancak O'Driscoll ve arkadaşlarından farklı olarak ve yine deneysel olarak MCL kesilmeden dirseğin posteriora çıkmadığı ve dirseğin valgus değil varus stresine maruz kalarak posteriora çıktığı ileri sürülmektedir.. ${ }^{[7]}$ Rhyou ve Kim, manyetik rezonans (MR) görüntüleme ile dirsek çıkı̆̆ı ya da çıkık olmadan dirsek çevresi yumuşak doku yapılarının yaralanması olan hastalarda hangi yumuşak dokuların yaralandığını araştırmışlardır. ${ }^{[8]}$ Posterolateral dirsek çıkıklarının valgus yüklenmesiyle MCL'yi ve onun üzerindeki pronator kasları yaralayarak başladığı, koronoid çıkıntının trokleadan ayrılmasıyla devam ettiği, koronoid çıkıntıda kopma kırığı olursa doğrudan posteriora çıkık oluştuğu, aksi takdirde PEFR'nin devam ederek radius başı ve posterior kapitellumda kemik kontüzyonu oluşturduğunu bildirmişlerdir. Posteromediyal dirsek çıkıklarının ise, varus yüklenmesi ile lateral ulnar kollateral bağ ve onun üzerindeki ekstansör kasların rüptürü ile başlayıp, ulnohumeral eklemin mediyalinde kemik kontüzyonu yarattığını ileri sürmüşlerdir. ${ }^{[8]}$

\section{SINIFLANDIRMA}

Dirsek çıkıkları, ana başlık olarak, basit ve kompleks dirsek çıkığı şeklinde ikiye ayrılır. Basit dirsek çıkığı için çıkığın yönü ve çıkığın olduğu zamanla müdahale arasında geçen süreye (çıkığın süresi) göre iki ayrı sınıflandırma kullanılır. Çıkığın yönüne göre, posterior (posterior, posterolateral, posteromediyal), anterior, lateral, mediyal, diverjan (anteroposterior ve transvers); çıkığın süresine göre, akut ( $<2$ hafta), subakut (2-6 hafta) ve kronik (>6 hafta) olarak sınıflandırılır. ${ }^{[1]}$ Çıkığın yönünü esas alan sınıflandırmaya, literatürde en nadir olarak bildirilen konverjan çıkık da (radyoulnar translokasyon $)^{[9]}$ eklenebilir.

\section{KLINIKK VE RADYOLOJIK DEĞERLENDIRME}

Bir travma sonrası dirsekte şişlik ve şekil bozukluğu ile gelen hastada, dirsek çıkığından şüphe edilir. İlk radyolojik değerlendirme ön-arka ve yan radyografik incelemeyle yapılır ve tanı konur. Radyografiyle, çıkığın yönüne ve dirsek bölgesi ve çevresi kırık olup olmadığına bakılmalıdır. Özellikle adolesanlarda, sağlam taraf dirsekle karşılaştırmalı grafi çekilmeli, mediyal ve lateral epikondil kopma kırıkları değerlendirilmelidir. Bağ yaralanmasının radyografik bulgusu olarak "drop" belirtisi (drop sign) tanımlanmıştır. ${ }^{[10]}$ Bu bulgu, dirsek çıkığı redüksiyonundan sonra lateral radyografide troklea ile olekranon arasındaki mesafenin artması olarak tanımlanmıştır. Ulnohumeral aralığın kontrol grafilerinde de $4 \mathrm{~mm}$ ve üzeri ölçümlerle sebat ettiği olgularda, dirsekte cerrahi gerektirecek ciddi bir bağ yaralanması olduğuna hükmedilebileceği bildirilmiştir. ${ }^{[10]}$ Eklem aralığındaki genişleme, eklem içine tuzaklanan osteokondral kırık parçalarını da akla getirmelidir (Şekil 2. a, b). ${ }^{[11]}$ Çıkığın nasıl oluştuğu ayrıntılı olarak sorgulanmalı, damar-sinir lezyonu redüksiyon öncesi ve sonrası kontrol edilmelidir. Redüksiyon sonrası bilgisayarlı tomografi (BT) ve üç boyutlu bilgisayarlı tomografi (3D-BT) her olguda çekilmeli, eklem çevresi kırık ve eklem içi kırık parçası kontrolü yapılmalıdır (Şekil 2. c-e). BT ve 3D-BT ameliyat yapılacak olgularda ameliyat öncesi planlama için de elzem bir tetkiktir. MR tetkikinin kullanımı sınırlıdır; yalnız yumuşak doku yaralanması olan instabil dirseklerde yumuşak doku yaralanmasının derecesini tespit etmede, eklem içi osteokondral kırık parçalarının daha ayrıntılı görüntülenmesinde, interossöz bağ yaralanması şüphesinde ve kronik instabilitede yararlı bilgi verebilir.

\section{TEDAVi}

Dirsek çıkığında acilen yapılması gereken birincil tedavi, kapalı redüksiyondur. Bu işlem genel ya da bölgesel anestezi altında ve skopi kontrolüyle yapılmalıdır. Kapalı redüksiyon manevrası, hasta sırtüstü ya da yüz üstü yatarken yapılabilir. En sık görülen posterior dirsek çıkığında tercih edilen yüzüstü pozisyondur. Hasta yüzüstü yatarken dirsek çıkığı olan ekstremite aşağıya sarkıtılır. Asistan koldan yukarıya doğru karşı traksiyon yaparken, redüksiyonu yapan önce mediyolateral düzlemde olekranonu orta hatta getirir, sonra bir eliyle hastanın elini tutup traksiyon yaparken diğer eliyle olekranonu trokleaya doğru baskı uygulayarak iter ve dirsek eklemini redükte eder. ${ }^{[12]}$ Nadir rastlanılan öne çıkıklarda, sırtüstü pozisyonda aynı teknik uygulanır; ancak olekranon posteriora itilerek redüksiyon sağlanır. Diverjan çıkıkta ise, ya önce proksimal radyoulnar eklem redükte edilir ve sonra ön kol humerusa redükte edilir ya da önce radius humerusa, sonra da ulna humerusa ayrı ayrı redükte edilir. ${ }^{[13]}$ Konverjan dirsek çıkıklarında açık redüksiyon gerekir. ${ }^{[14]}$

Akut çıkık redüksiyonu sonrası stabilite kontrolü dirseği fleksiyondan ekstansiyona alırken yapılır. Dirsek $60^{\circ}$ ve altında ekstansiyona gelirken çıkıyorsa instabildir. Ön kol pronasyona alındığında dirsek eklemi çıkmıyorsa, ön kol pronasyonda menteşeli breys uygulanır. Ön kol pronasyona alınmasına rağmen $60^{\circ}$ 'nin altında dirsek eklemi çıkıyorsa, $60^{\circ}$ 'de ekstansiyon bloğu konularak breys uygulanır. Ön kol pronasyondayken $60^{\circ}$ 'nin üzerindeki fleksiyon değerlerinde dirsek eklemi çıkıyorsa, bağ tamiri ve tamire rağmen çıkan dirseğe eksternal fiksatör uygulamak gerekir. ${ }^{[1]}$ 

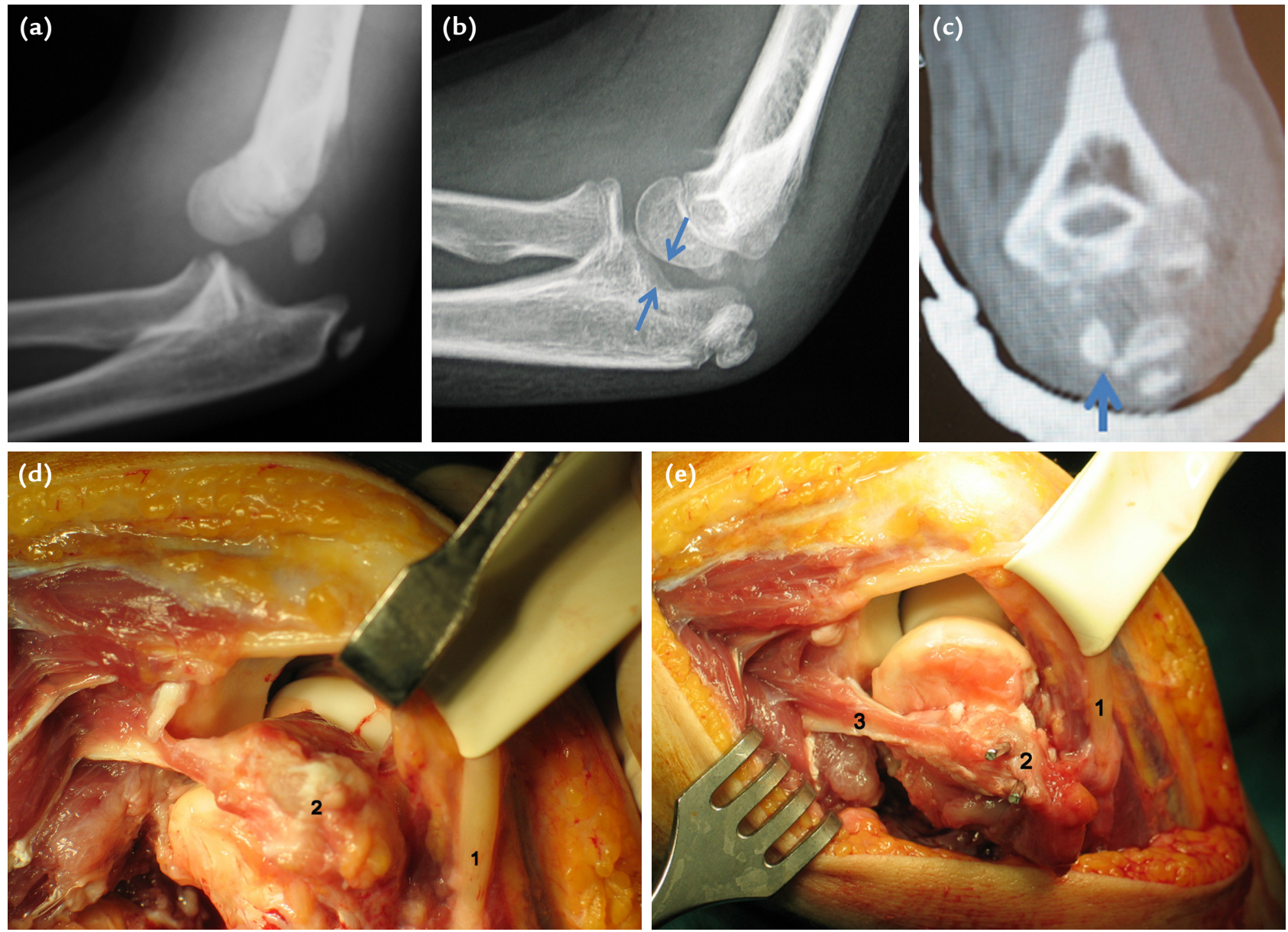

Şekil 2. a-e. On üç yaşındaki erkek çocukta posteriora dirsek çıkı̆̆ı, mediyal epikondil kopma kırığı (a). Başka bir merkezde tedavi edilen olguya kapalı redüksiyon, 25 gün alçı atel tespiti ve bir ay süreyle fizik tedavi uygulanıyor. Hasta, hareket kısıtlılığı nedeniyle hastanemize başvurdu. Lateral grafisinde “drop” belirtisi var ve oklarla gösterilen eklem aralığı mesafesi artmış (b). Olgunun BT ve 3D-BT tetkikinde, eklem içindeki mediyal epikondil görülüyor $(o k, c)$. Olgunun ameliyat sırasında görüntüsü: Ulnar sinir (1), Takla atarak eklem içine girmiş trokleayı kapatan mediyal epikondil (2) (d). Olgunun ameliyat sırasında görüntüsü: Ulnar sinir (1), Medial epikondil ters takla attırılarak eklem içinden çıkarılmış ve anatomik yerine iki adet Kirschner teliyle tespit edilmiş (2), MCL'nin anterior bandı (3) (e).

"Drop" belirtisi tespit edilen olguların aktif hareket ve varus stresi önlenerek tedavi edilebileceği bildirilmiştir. ${ }^{[15]}$ Ancak bu olgularda BT tetkiki yapılarak eklem içi osteokondral kırık parçası araştırılmalı, MR tetkiki yapılarak MCL ve LCL kompleksi ile ekstansör ve pronator kaslardaki yaralanma derecesi tespit edilmelidir. $M C L$ ve $L C L$ kompleksi yaralanması ile birlikte ekstansör ve pronator kaslar da yırtıksa, cerrahi tedaviyle yumuşak doku tamiri yapılmalıdır (Şekil 3).

\section{TEDAVI SONRASI TAKIP VE REHABILITASYON}

Kapalı redüksiyon sonrası immobilizasyon süresi üç haftanın üzerinde olan olguların fonksiyonel sonuçlarının, immobilizasyon süresi üç haftanın altında olanlara göre anlamlı derecede kötü olduğu bildirilmiştir. ${ }^{[16]}$ Kapalı redüksiyonla stabil redükte olan olgularda 10 gün süreyle dirsek üstü alçı atel ya da omuz-kol askısı uygulanır ve dirsek bölgesindeki ödemin gerilemesi sağlanır. Dirsek ekleminde sertlik gelişmemesi için, en geç 10. günde hareket başlanır. İletişimi iyi olan hastada redüksiyon sonrası hemen harekete başlanmalı, yerçekimini bertaraf etmek ve omuzu sabitlemek için yatar pozisyonda ve aktif fleksiyon-ekstansiyon egzersizi olarak yapılmalıdır. Pasif egzersiz, eklemde kanama, hastada ağrılı uyaran ve heterotopik kemikleşme riski yaratacağından uygulanmamalıdır. Kapalı redüksiyonla tedavi edilen hastalarda redüksiyonun konsantrik devam 

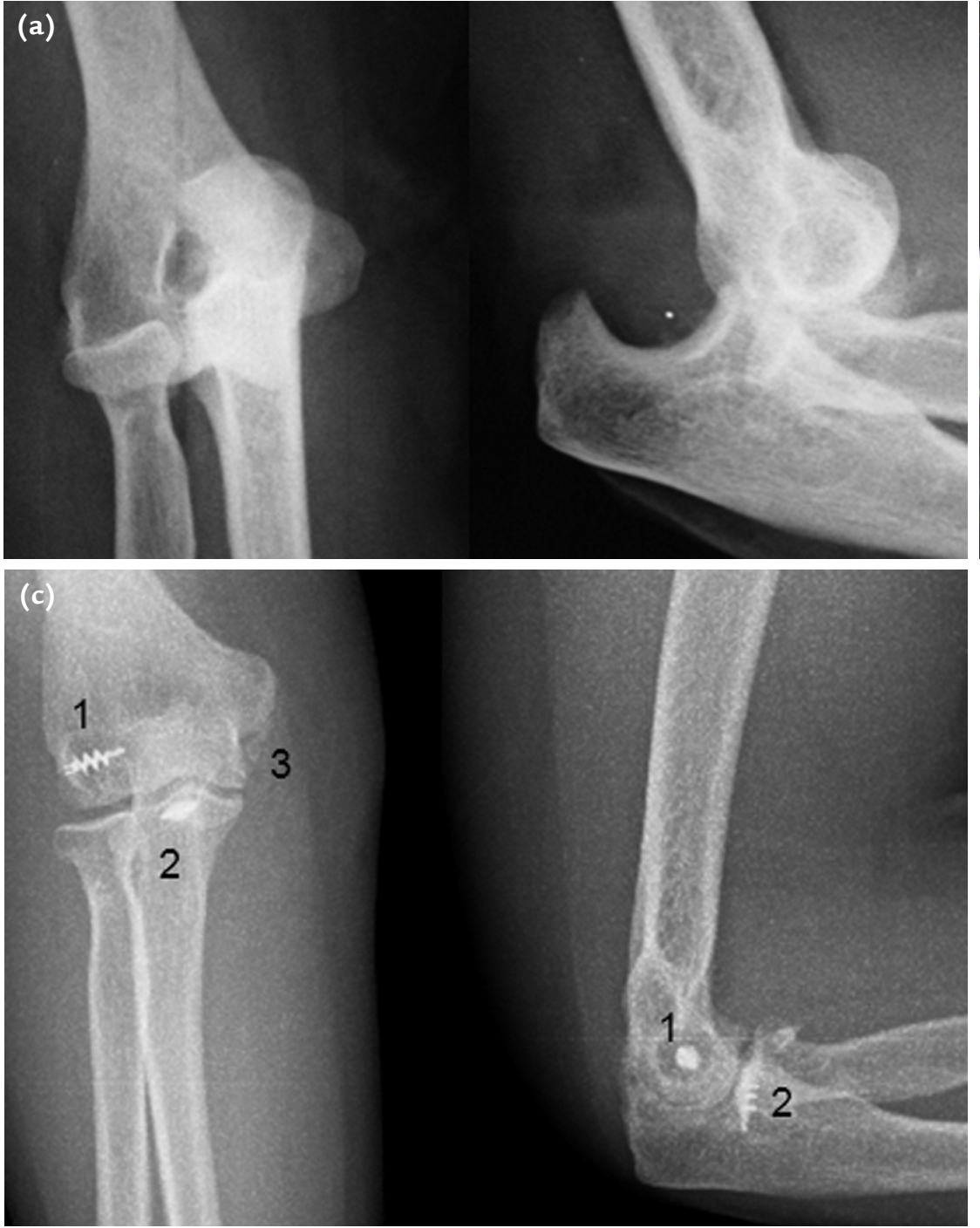

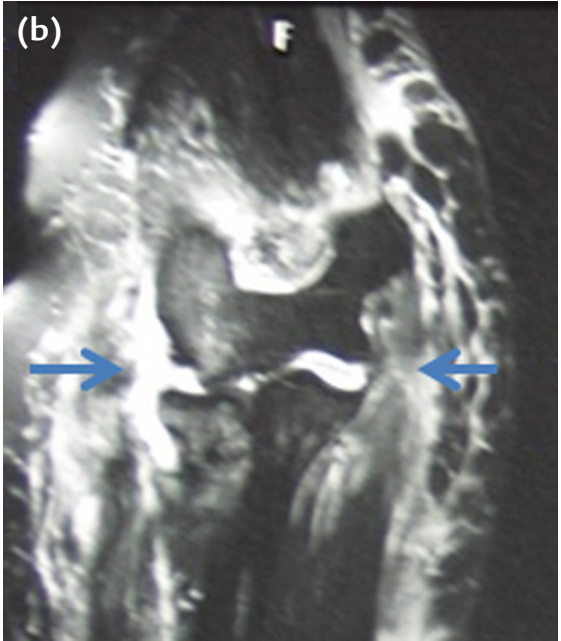

Şekil 3. a-c. Kırk altı yaşındaki kadında posterior dirsek çıkığı, koronoid çıkıntıda eklem dışı kopma kırığı (a). Redüksiyon sonrası stabilite testinde $60^{\circ}$ fleksiyonun üzerinde dahi dirsek lukse oluyor. MR görüntülemede, LCL kompleksi ve ekstansor kasların origosundaki yırtık (sol ok) ile MCL kompleksi ve pronator kasların origosundaki yırtık (sağ ok) görülüyor (b). Olgunun ameliyat sonrası 11 aylık görüntüleri (c): LCL kompleksi ve ekstansor kasların onarımı için kullanılan ankor (1), Koronoid çıkıntı kopma kırığı (brakiyalis kası ve anterior kapsül) onarımı için kullanılan ankor (2), MCL kompleksi ve pronator kasların yırtığı primer olarak onarılmış (3). Sonuç: Dirsek eklem hareket genişliği (ROM), $10^{\circ}-140^{\circ}$; ön kol pronasyon-supinasyon, $90^{\circ}-90^{\circ}$. ettiği, birinci ve ikinci hafta çekilen radyografilerle doğrulanmalıdır.

Bağ tamiri yapılan olgulara menteşeli breys verilerek, breys içinde fleksiyon-ekstansiyon hareketi yaptırılır. Breys dört hafta kullanılır. Kronik instabilitesi olan olgularda uygulanan bağ rekonstrüksiyonlarında bu süre altı haftaya uzatılır. Eksternal fiksatör uygulaması yapılan hastalarda fiksatör altı hafta muhafaza edilir. Fiksatör tercihan menteşeli olmalıdır ve bu sürede hasta fleksiyon ve ekstansiyon hareketlerini yapmalıdır. Menteşeli fiksatör uygulamasında, deneyim yetersiz ise, dirseği konsantrik redüksiyonda tutmak kaydıyla dirsek $90^{\circ}$ fleksiyonda sabit eksternal fiksatör de uygulanabilir; bu durumda fiksatör 3-4 hafta tutulmalı, sonra menteşeli breyse geçilmeli ve harekete başlanmalıdır. ${ }^{[11]}$

\section{TEDAVI SONUÇLARI}

Basit dirsek çıkıklarının kapalı redüksiyon ile stabil olanlarında, sonuçların \%75-100 arasında iyi ya da mükemmel olduğu bildirilmektedir. ${ }^{[17]}$ Fleksiyon, pronasyon ve supinasyon hareketleri etkilenmemekte, ekstansiyon ise $15^{\circ}$ ye kadar kısıtlı kalmaktadır. ${ }^{[11]}$ Bir çalışmada ise, mükemmel sonuçlar \%95 olguda tespit edilmesine rağmen, subjektif olarak hastaların \%19'unun kendini tam olarak iyileşmiş hissettiği bildirilmiştir. ${ }^{[18]}$ Bu çalışmada, hastalardaki en sık yakınmanın dirsekte sertlik hissi, ağır iş ve sportif aktivite sırasında oluşan ağrı ve hareket kısıtlılığı olduğu belirtilmiştir. Bir başka çalışmada, kapalı redüksiyon sonrası hemen hareket verilen olguların fonksiyonel sonuçları ortalama 14 gün alçı atel uygulananlara göre anlamlı derecede yüksek bulunmuş̧tur. ${ }^{[19]}$ 
Stabil olmayan basit dirsek çıkığı, tüm basit dirsek çıkıklarının \%1-2'sidir.[11] Bu olguların cerrahi tedavili sonuçlarının, kapalı redüksiyonla tedavi edilen basit dirsek çıkıklarının sonuçları ile anlamlı fark göstermediği bildirilmiştir. ${ }^{[20]}$ Bir çalışmada, stabil olmayan basit dirsek çıkığı olgularının \%29'unda bağ tamiri sonrası rezidüel subluksasyon ya da dislokasyon görüldüğgu bildirilmiş, bu nedenle bağ tamiri yapılan olgularda eksternal fiksatör uygulanmasının daha uygun olacağı kanaatine varılmıştır. ${ }^{[21]}$ Aynı çalışmada, düşkün hastalarda ameliyat süresini kısaltmak ve genel anesteziden kaçınmak için eklemin perkütan tellerle tespit edilebileceği (olekranondan humerusa doğru), koronoid çıkıntının kopma kırıklarının varus posteromediyal rotasyonel instabilitenin bulgusu olduğu ve bu tip yaralanmaların posterolateral rotasyonel instabilitelere göre daha instabil olduğu bildirilmiştir.

\section{KOMPLIKASYONLAR}

\section{Kontraktür}

En sık rastlanan fleksiyon kontraktürüdür ve özellikle anterior kapsüldeki sertleşmeye bağlıdır. Fleksiyon kontraktürünün diğer bir önemli nedeni ise ekstansiyon bloğu oluşturan olekranon çukurundaki osteofitler ve debris materyalleridir. ${ }^{[22]} \mathrm{Bu}$ komplikasyonun doğrudan immobilizasyon süresiyle ilişkisi vardır. Üç haftanın üzerinde yapılan tespitlerde en az $30^{\circ}$ fleksiyon kontraktürü gözlenebileceği, tespit süresi beş gün ve altında tutulursa fleksiyon kontraktürünün $3^{\circ}$ ye kadar indirilebileceği bildirilmiştir. ${ }^{[23]}$ Kontraktür tedavisinde önce ameliyatsız tedavi denenmelidir. Aktif hareket ile hareket açıklığını arttırıcı egzersizler ve progresif statik atelleme en etkili yöntemlerdir. ${ }^{[24]}$ Genel anestezi ile manipülasyon yapılarak eklem hareket açıklığını arttırma yöntemi, dirsek bölgesi için genellikle olumsuz sonuçlar verir ve hareket kısıtlılığı artabilir. Bu nedenle, yalnız genç ve motive olabilen hastada, kontraktür başlar başlamaz erken dönemde uygulanmalıdır. Bu tip hastalara interskalen kateter ile ağrı pompası takılmalı ve üç hafta süreyle ağrı kesilerek manipülasyonla elde edilen hareket açıklığında egzersize devam edilmelidir. Bu sürede progresif statik atelleme uygulanarak kazanılan hareket açıklıklarında dokunun maksimum gerilmesi sağlanır. Ayrıca, progresif statik atellemeye gece uygulanan statik atelleme eklenerek kazanilan hareket korunur. Bu tedaviye 4-6 ay devam edilmeli, sonuç alınmazsa cerrahi tedaviye geçilmelidir. Cerrahi tedavi açık ya da artroskopik yapılabilir. Açık cerrahi tedavide mediyal, lateral, mediyal ve lateral ya da posterior yaklaşımlar kullanılabilir. Mediyal ve lateral çift insizyon tercih edilen girişimdir; lateral yaklaşım (kolon girişimi) ile anterior, lateral ve posterior kompartmanlarda gevşetme sağlanırken, mediyal girişimle ulnar sinirin anteriora transpozisyonu yapılır. Tek bir posterior insizyonla da tüm kompartmanlara ulaşmak mümkündür. Sert dirseğe artroskopik girişim ise nörovasküler komplikasyonların yüksek olması nedeniyle deneyimli cerrahlar tarafından yapılmalıdır. Kontraktür gevşetmesi sonrası rehabilitasyon, basit dirsek çıkığında uygulananla aynıdır.

\section{Heterotopik kemikleşme (HO)}

Dirsek travması sonrası $\mathrm{HO}$ için risk etmenleri; daha önce $\mathrm{HO}$ geçirilmiş olması, 60 yaşın üzerinde erkek, hipertrofik osteoartrit, diffüz idiyopatik hiperostoz, Paget hastalığı ve ankilozan spondilittir. Diğer risk etmenleri olarak; zorlamalı pasif hareket, cerrahi girişimin travmadan 48 saatten fazla gecikilerek yapılması, ikincil ya da revizyon cerrahi girişim uygulanması, travmatik beyin hasarı, vucudun \%20'sini içeren ya da dirsek bölgesindeki yanıklar da sayılabilir. ${ }^{[22]}$ Bir seride, basit dirsek çıkığı olan hastaların \%67'sinde (21 hastanın 14'ünde) HO geliştiği ancak HO gelişen hastalarla gelişmeyenler arasında fonksiyonel yönden anlamlı fark olmadığı bildirilmiştir. ${ }^{[17]}$ Risk ölçütlerini taşıyan hastalarda profilaksiye hemen başlanmalıdır; HO başladıktan sonra yapılan profilaksinin etkisi yoktur. Proflaktik tedavide nonsteroid antiinflamatuvar ilaçlar (özellikle indometazin 25mg, 3×1/gün, 1-6 hafta süreyle) ve radyoterapi (tek doz 700cGy ya da 5 eşit doz toplam 1000cGy; dirsek travmasından sonra 72 saat ya da ameliyat öncesi 4 saat ya da ameliyat sonrası 48 saat içerisinde) kullanılır. Hareket kısıtlılığına neden olan ve ameliyatsız tedavilere cevap vermeyen HO'da cerrahi rezeksiyon gerekir. Cerrahinin zamanlaması tartışmalı olmakla beraber altı ay bekledikten sonra yapılmasının uygun olacağı bildirilmektedir. ${ }^{[22]}$

\section{Nörovasküler yaralanma}

Basit dirsek çıkığı sonrası sinir yaralanması, redüksiyon manevrası sırasında sinirin traksiyonuna, eklem içine tuzaklanmasına ya da geç dönemde çevre doku tarafından kronik kompresyonuna bağlı olabilir. En sık ulnar sinir yaralanması görülmekte, bunu median sinir izlemektedir. Sinir yaralanması sıklığı \%1-17 arasında bildirilmektedir. ${ }^{[22]}$ Ulnar sinir yaralanması, akut dönemde nöropraksi ve geç dönemde yumuşak doku fibrosisi içinde sıkışma tarzında karşımıza çıkar; nöropraksi kendiliğinden geriler. Ulnar sinirin sıkışma bulguları varsa elektromiyografik tetkik ile doğrulanır. Tedavisi, ulnar sinirin dekompresyonu ve anteriora transpozisyonudur. Median sinirin eklem içine tuzaklanması özellikle çocuklarda görülür. Bunun nedeni, mediyal epikondilin kopma kırı̆̆ının çocuk dirsek çıkıklarının \%30'unda rastlanmasıdır. Median sinirin üç 
tipte tuzaklanması bildirilmiştir; Tip 1'de, kırık olan mediyal epikondilin arkasına kayarak ekleme posteriordan girer ve anteriordan çıkar; Tip 2'de, kırık olan mediyal epikondilin kırık hattına girer ve zamanla gelişen kallus dokusunda sıkışır; Tip 3'te ise brakiyalis kası ya da anterior kapsüldeki yırtıktan anteriordan eklem içine girer, üzerine katlanarak yine anteriordan eklemi terk eder. ${ }^{[25]}$ Kronik median sinir tuzaklanmasında Matev belirtisi tanımlanmıştır; bu, radyografik olarak posteromediyal epikondilin üzerinde sklerotik bir çökme alanının görülmesidir. ${ }^{[26]}$ Klinik olarak, redüksiyon sonrası dirsekte ağrısı kesilmeyen ve ön kolda yanma şikayetleri olanlarda; radyografik olarak ise mediyal epikondil kırığı olan ve redüksiyon sonrası mediyal eklem aralığında genişlemesi olan olgularda median sinir tuzaklanmasından şüphe edilmelidir. Tanı konulmasında MR görüntülemeden yararlanılabilir. ${ }^{[27]}$ Tedavisi, median sinirin eksplorasyonu ve dekompresyonudur.

Dirsek çıkığında brakiyal arteryaralanması nadirdir; sıklığı \%0,3-1,7 arasında bildirilmektedir. ${ }^{[28]}$ Özellikle açık çıkıklarda ve kırıklı çıkıklarda görülür; deplasman derecesi ve yaralanma şiddeti ile doğru orantılı olarak yaralanma riski artar. ${ }^{[22,28]}$ Redüksiyon öncesi ve sonrası distal nabızların alınamaması, parmaklarda iskemi ve konjesyon, elde soğukluk ve uyuşukluk brakiyal arter yaralanmasını akla getirir. Bu durumda Doppler ve anjiyografi tetkikleri yapılmalıdır. Brakiyal arterde yaralanma varsa acil tamir gerekir; primer tamir tercih edilir, ancak genellikle safen ven grefti ile tamir gerekir. ${ }^{[22]}$

\section{Essex-Lopresti yaralanması}

Essex-Lopresti yaralanması, interosseöz membran, distal radyoulnar eklem ve proksimal radyoulnar eklem yaralanmalarını içerir. Distal radyoulnar eklem yaralanması dirsek çıkıklarının radius başı ya da boynu kırıklarıyla birlikte olanlarıyla daha sıklıkla görülmekle birlikte, basit dirsek çıkıklarında da görülebilir. Bu nedenle, distal radyoulnar eklemin klinik ve radyografik değerlendirmesi her dirsek çıkığı olan hastada yapılmalıdır; şüpheli durumlarda sağlam tarafın radyografileriyle karşılaştırılmalıdır.

\section{Rezidüel instabilite}

Basit dirsek çıkıklarından sonra, nadir gözükse de rezidüel instabilite gelişebilir; en sık posterolateral instabilite olarak görülür. Posterolateral instabilite, lateral ulnar kollateral bağın yetersizliğini gösterir. Tanısında lateral "pivot shift" korkutma testi, lateral "pivot shift" testi, posterolateral rotatuvar çekmece testi ve "stand up" testi kullanılır; lateral stres radyografi, rotatuvar radius başı subluksasyonunu gösterebilir. ${ }^{[29]}$ Tedavisinde triseps fasyası ya da plantaris, semitendinosus, gracilis tendonlarından herhangi biriyle lateral ulnar kollateral bağ rekonstrüksiyonu yapilır.

\section{KAYNAKLAR}

1. Sheps DM, Hildebrand KA, Boorman RS. Simple dislocations of the elbow: evaluation and treatment. Hand Clin 2004;20(4):389-404.

2. Saati ZA, McKee MD. Fracture-dislocation of the elbow: diagnosis, treatment, and prognosis. Hand Clin 2004(4);20:405-14.

3. O'Driscoll SW. Elbow dislocations. In: Morrey BF, editor. The elbow and its disorders. 3rd ed. Philadelphia: WB Saunders; 2000. p.409-20.

4. Josefsson PO, Nilsson BE. Incidence of elbow dislocation. Acta Orthop Scand 1986;57(6):537-8.

5. Morrey BF, An KN. Articular and ligamentous contributions to the stability of the elbow joint. Am J Sports Med 1983;11(5):315-9.

6. O'Driscoll SW, Morrey BF, Korinek S, An KN. Elbow subluxation and dislocation. A spectrum of instability. Clin Orthop Relat Res 1992;(280):186-97.

7. Deutch SR, Olsen BS, Jensen SL, Tyrdal S, Sneppen O. Ligamentous and capsular restraints to experimental posterior elbow joint dislocation. Scand J Med Sci Sports 2003;13(5):311-6.

8. Rhyou IH, Kim YS. New mechanism of the posterior elbow dislocation. Knee Surg Sports Traumatol Arthrosc 2012;20(12):2535-41. CrossRef

9. Carey RP. Simultaneous dislocation of the elbow and the proximal radio-ulnar joint. J Bone Joint Surg $\mathrm{Br}$ 1984;66(2):254-6.

10. Coonrad RW, Roush TF, Major NM, Basamania CJ. The drop sign, a radiographic warning sign of elbow instability. J Shoulder Elbow Surg 2005;14(3):312-7.

11. Cohen MS, Hastings $H$ 2nd. Acute elbow dislocation: evaluation and management. J Am Acad Orthop Surg 1998;6(1):15-23.

12. Meyn MA Jr, Quigley TB. Reduction of posterior dislocation of the elbow by traction on the dangling arm. Clin Orthop Relat Res 1974;(103):106-8.

13. Hildebrandt KA, Patterson SD, King GJ. Acute elbow dislocations: simple and complex. Orthop Clin North Am 1999;30(1):63-79.

14. Carey RP. Simultaneous dislocation of the elbow and the proximal radio-ulnar joint. J Bone Joint Surg $\mathrm{Br}$ 1984;66(2):254-6.

15. Duckworth AD, Kulijdian A, McKee MD, Ring D. Residual subluxation of the elbow after dislocation or fracturedislocation: treatment with active elbow exercises and avoidance of varus stress. J Shoulder Elbow Surg 2008;17(2):276-80.

16. Schippinger G, Seibert FJ, Steinböck J, Kucharczyk M. Management of simple elbow dislocations. Does the period of immobilization affect the eventual results? Langenbecks Arch Surg 1999;384(3):294-7.

17. Lansinger O, Karlsson J, Körner L, Måre K. Dislocation of the elbow joint. Arch Ortop Trauma Surg 1984;102(3):183-6. 
18. Kesmezacar H, Sarıkaya IA. The results of conservatively treated simple elbow dislocations. Acta Orthop Traumatol Turc 2010;44(3):199-205. CrossRef

19. Maripuri SN, Debnath UK, Rao P, Mohanty K. Simple elbow dislocation among adults: a comparative study of two different methods of treatment. Injury 2007;38(11):1254-8.

20. Josefsson PO, Gentz CF, Johnell O, Wendeberg B. Surgical versus non-surgical treatment of ligamentous injuries following dislocation of the elbow joint. A prospective randomized study. J Bone Joint Surg Am 1987;69(4):605-8.

21. Duckworth AD, Ring D, Kulijdian A, McKee MD. Unstable elbow dislocations. J Shoulder Elbow Surg 2008;17(2):281-6.

22. Martin BD, Johansen JA, Edwards SG. Complications related to simple dislocations of the elbow. Hand Clin 2008;24(1):925. CrossRef

23. Mehlhoff TL, Noble PC, Bennett JB, Tullos HS. Simple dislocation of the elbow in the adult: results after closed treatment. J Bone Joint Surg Am 1988;70(2):244-9.
24. Bonutti PM, Windau JE, Ables BA, Miller BG. Static progressive stretch to reestablish elbow range of motion. Clin Orthop Relat Res 1994;(303):128-34.

25. Hallett J. Entrapment of the median nerve after dislocation of the elbow. A case report. J Bone Joint Surg $\mathrm{Br}$ $1981 ; 63-B(3): 408-12$

26. Matev I. A radiological sign of entrapment of the median nerve in the elbow joint after posterior dislocation. A report of two cases. J Bone Joint Surg Br 1976;58(3):353-5.

27. Akansel G, Dalbayrak S, Yilmaz M, Bekler H, Arslan A. MRI demonstration of intra-articular median nerve entrapment after elbow dislocation. Skeletal Radiol 2003;32(9):537-41.

28. Ayel JE, Bonnevialle N, Lafosse JM, Pidhorz L, Al Homsy M, Mansat P, Chaufour X, Rongieres M, Bonnevialle P. Acute elbow dislocation with arterial rupture. Analysis of nine cases. Orthop Traumatol Surg Res 2009;95(5):343-51. CrossRef

29. O'Driscoll SW. Classification and evaluation of recurrent instability of the elbow. Clin Orthop Relat Res 2000;(370):34-43. 